Glycerol electrooxidation on Pd modified Au surfaces in alkaline media: Effect of the deposition method

Gisele A. B. Mello, Carlos Busó-Rogero, Enrique Herrero, and J. M. Feliu

Citation: J. Chem. Phys. 150, 041703 (2019); doi: 10.1063/1.5048489

View online: https://doi.org/10.1063/1.5048489

View Table of Contents: http://aip.scitation.org/toc/jcp/150/4

Published by the American Institute of Physics 


\title{
Glycerol electrooxidation on Pd modified Au surfaces in alkaline media: Effect of the deposition method
}

\author{
Gisele A. B. Mello, ${ }^{1,2}$ Carlos Busó-Rogero, ${ }^{1, a)}$ Enrique Herrero, ${ }^{1}$ and J. M. Feliu ${ }^{1}$ \\ ${ }^{1}$ Instituto de Electroquímica, Universidad de Alicante, Ap. 99, E-03080 Alicante, Spain \\ ${ }^{2}$ Curso de Licenciatura em Química, Instituto de Ciências da Educação, Universidade Federal do Oeste \\ do Pará, Avenida Marechal Rondon, s/n, 68040-070 Santarém, PA, Brazil
}

(Received 15 July 2018; accepted 17 August 2018; published online 8 November 2018)

\begin{abstract}
The catalytic effect of Pd on gold electrodes for glycerol oxidation is evaluated for Pd-Au surfaces prepared using three different methods: irreversible adsorption of palladium by a simple immersion of a gold electrode in palladium solution, the deposition of palladium on the gold substrate by a step potential from 1 to $0.75 \mathrm{~V}$, and the forced deposition of palladium on the gold electrode with the help of a reducing hydrogen atmosphere. Voltammetry has been used for the electrochemical characterization of the Pd-Au deposits and to determine its reactivity towards glycerol oxidation, whereas FTIR experiments have allowed detecting adsorbed species and products formed during the oxidation reaction. $\mathrm{Pd}-\mathrm{Au}$ surfaces prepared by irreversible adsorption are the electrodes that show the highest activity for the glycerol complete oxidation to carbonate, whereas $\mathrm{Pd}-\mathrm{Au}$ surfaces made by the step potential are the catalyst that exhibits the highest rate for the formation and adsorption $\mathrm{CO}$ before carbonate production, poisoning the surface and diminishing their electrocatalytic properties. In addition to carbonate, glycerate, glycolate, and formate are detected as oxidation products. The integrated bands of the spectra are used to give quantitative information for comparing the product distribution of the different Pd-Au deposits prepared. Published by AIP Publishing. https://doi.org/10.1063/1.5048489
\end{abstract}

\section{INTRODUCTION}

During the last thirty years, many efforts have been devoted to direct alcohol fuel cells (DAFCs) in which alcohols, such as methanol and ethanol, are used as fuels in substitution to hydrogen in fuel cell anodes. The major advantages in the use of alcohols are the increased safety and a higher volumetric energy density as compared with hydrogen. In this perspective, glycerol can also be used in a DAFC because it is a non-toxic bio-renewable chemical feedstock with a low price, which can be obtained from the production of biodiesel and the hydrolytic splitting of vegetable oils. ${ }^{1-3}$ In addition, glycerol is also used for pharmaceuticals and cosmetic proposes, and many of its oxidation products are useful intermediates or valuable fine chemicals that are produced through expensive and/or highly toxic chemical processes. ${ }^{3-7}$ In this framework, it is essential to understand the oxidation mechanism of glycerol electro-oxidation to develop more efficient and selective electrocatalysts for both uses.

The activity and selectivity of the electro-oxidation of alcohols are influenced by several factors. The most important parameter that affects the electrochemical reaction is the catalyst itself: its nature, structure, and composition play a critical role in the reactivity. ${ }^{4-6}$ All of them alter the electronic structure of the surface, which, in turn, affects the interaction of the surface with the reactants and intermediate species, modifying the reaction kinetics. The untangling of the oxidation

Note: Advanced online article.

a)E-mail: carlos.buso@ua.es mechanism requires, necessarily, to study the effects of all these parameters.

The electronic structure and, in consequence, the chemisorption properties of the electrocatalyst can be obtained not only by modification of its bulk composition but also by simply altering the surface composition by deposition of metallic adlayers and adatoms. Regarding this effect, it has been shown that the preparation of the catalysts significantly affects the outcome surface structure and composition which, in turn, modifies the electrocatalytic response of the material. Then, understanding the effects of the modification of a given substrate with ad-atoms in the reaction mechanism and kinetics is a crucial issue to obtain better electrocatalysts. ${ }^{4,8-12}$ It is a well-known fact that some bimetallic catalysts show better catalytic activity than the corresponding pure monometallic ones. This is the case, for instance, of Pd adlayers deposited on Au substrates. Au-Pd surfaces are catalytic to several reactions, including the electro-oxidation of formic acid, ${ }^{13}$ ethanol, ${ }^{6,14}$ and glycerol. ${ }^{3-5,7,15,16}$ However, the relationship between the surface structure and reactivity is not totally understood, despite it is known that the activity of Au-Pd surfaces depends on the deposit thickness and the substrate structure as well as the electronic and geometric effects. ${ }^{14,15,17,18}$ In this sense, the stability of Pd-Au adlayers has been tested by Kibler et al.,${ }^{19-21}$ depositing palladium on gold single crystal electrodes with a well-known surface structure. Using Scanning Tunneling Microscopy (STM), the epitaxial growth of palladium in the gold basal planes is observed.

Focusing on the glycerol electro-oxidation on gold and palladium combined surfaces, $\mathrm{PdAu} / \mathrm{C}$ supported catalysts 
prepared by electron beam irradiation ${ }^{4,5}$ and the wet method ${ }^{3}$ were shown to be more active and tolerant to surface poisoning than $\mathrm{Pd} / \mathrm{C}$ catalysts synthesized by the same methods. The authors linked the increase in the catalytic activity when adding $\mathrm{Au}$ at $\mathrm{Pd} / \mathrm{C}$ to the synergistic effect of gold and palladium. $\mathrm{Au}$ atoms adsorbed on the surface lead to an increase in the concentration of adsorbed $\mathrm{OH}$ species in proximity to $\mathrm{Pd}$, favoring the oxidation of glycerol and the formation of other intermediaries adsorbed on the Pd surface such as glyceraldehyde and glycerate ions. ${ }^{3-7}$ Mougenot et al. also reported that the modification of the Pd surface with Au atoms leads to an increase in the catalytic activity towards glycerol electro-oxidation through the bifunctional mechanism. ${ }^{7}$ However, they also pointed out that their PdAu catalysts prepared by plasma sputtering are more active to oxidize glycerol than those synthesized by the wet method due to the final electrode structure and surface composition, that is, the presence of non-alloyed gold sites on the material surface seems to be responsible for the enhancement of the catalytic activity.

In this context, it is evident that the preparation method plays a significant role in the glycerol electro-oxidation. Among simple deposition methods for adatom deposition, we can consider (i) the "irreversible adsorption" (or spontaneous deposition), in which the metallic deposit is formed in the open circuit potential (OCP) through redox reactions on the catalyst surface; ${ }^{8}$ (ii) the "forced deposition" when a reducing agent (such as $\mathrm{H}_{2}$ ) is used $;^{8}$ and (iii) the "step potential method" in which the metallic deposit is obtained by reducing the ionic species using a controlled potential. ${ }^{22}$ The aim of this manuscript is to investigate the effect of the $\mathrm{Pd}$ deposit method on $\mathrm{Au}$ (poly) electrodes in the glycerol electro-oxidation reaction.

\section{EXPERIMENTAL}

An Au single crystal bead was used as the working electrode. The surface of this bead contains all the different surface contributions in a well-defined way, and it is very convenient as a model of the polycrystalline electrode. Prior to any experiment, it was flame annealed to remove organic impurities from the surface. To confirm that this was so, the voltammetric profile of the electrode was recorded in $0.1 \mathrm{M} \mathrm{NaOH}, 0.01 \mathrm{M}$ $\mathrm{HClO}_{4}$, and $0.05 \mathrm{M} \mathrm{H}_{2} \mathrm{SO}_{4}$, the same electrolytes used for the study of the glycerol electro-oxidation reaction (Fig. 1).
After the electrode cleaning and the initial characterization step, the Pd-Au surfaces were prepared using three different methods: (i) irreversible adsorption ( $\left.\mathrm{Pd}-\mathrm{Au}_{\mathrm{irr}}\right)$, in which the Au electrode is immersed for $5 \mathrm{~min}$ in a beaker containing a $\mathrm{Pd}^{2+}$ solution $\left(2.72 \times 10^{-3} \mathrm{M} \mathrm{PdSO}_{4}\right)$, (ii) forced Pd deposition ( $\left.\mathrm{Pd}-\mathrm{Au}_{\text {forced }}\right)$, where the electrode is immersed in the $\mathrm{Pd}^{2+}$ solution and transferred to a vessel with a reductive atmosphere $\left(\mathrm{H}_{2} / \mathrm{Ar}\right) ;{ }^{8}$ and (iii) step potential deposition ( $\left.\mathrm{Pd}-\mathrm{Au}_{\text {step }}\right)$, where the electrode is immersed in a cell containing a $10^{-4} \mathrm{M} \mathrm{PdSO}_{4}$ $+0.05 \mathrm{M} \mathrm{H}_{2} \mathrm{SO}_{4}$ solution and potential step from 1 to $0.75 \mathrm{~V}$ is applied for $300 \mathrm{~s}$, as described elsewhere. ${ }^{22}$ Independent of the Pd adsorption method, the electrode is, then, rinsed with ultrapure water and transferred to the electrochemical cell to characterize it by evaluating its voltammetric profile in $0.01 \mathrm{M} \mathrm{HClO}_{4}$. After that, its activity towards glycerol electro-oxidation was studied in a different electrochemical cell with a $0.1 \mathrm{M} \mathrm{NaOH}$ solution containing glycerol in a concentration range between $1 \times 10^{-4} \mathrm{M}$ and $1 \times 10^{-1} \mathrm{M}$. After the electrochemical experiments, $\mathrm{Pd}$ deposits were removed by immersing three times the electrode in a $25 \% \mathrm{HNO}_{3}$ solution and rinsing with water.

Spectroelectrochemical measurements were performed in a glass cell connected to a $\mathrm{CaF}_{2}$ prism beveled at $60^{\circ},{ }^{23}$ using the external reflection configuration. The IR spectra were obtained from the average of 100 interferograms with a resolution of $8 \mathrm{~cm}^{-1}$ using $p$-polarized light and are presented in absorbance units: $A=-\log \left[\left(R_{1}-R_{2}\right) / R_{1}\right]$, where $R_{1}$ and $R_{2}$ are the reflectance values corresponding to the singlebeam spectra recorded at the sample at the reference potential, respectively. The reference spectrum was taken at $0.1 \mathrm{~V}$ for all the experiments. Positive bands indicate the increase in the concentration of the species, and negative bands correspond to species consumed in the sample potential with respect to the reference potential. Spectra were acquired employing a Nicolet (Model 8700) spectrometer, equipped with an MCT (Mercury-Cadmium-Telluride) detector.

The experiments were carried out at room temperature in a three-electrode electrochemical cell, using an Au wire as a counter-electrode. All the potentials are referred to the reversible hydrogen electrode (RHE). Ar (N50, Air Liquide) is used for deoxygenating the electrochemical cell. Solutions were prepared using $\mathrm{HClO}_{4}$ (Merck $60 \%$ for analysis), $\mathrm{H}_{2} \mathrm{SO}_{4}$ (Merck 96\% Suprapur ${ }^{\circledR}$ ), $\mathrm{NaOH}$ (Merck $99.99 \%$ Suprapur), and glycerol (Calbiochem) in ultrapure water (Elga).
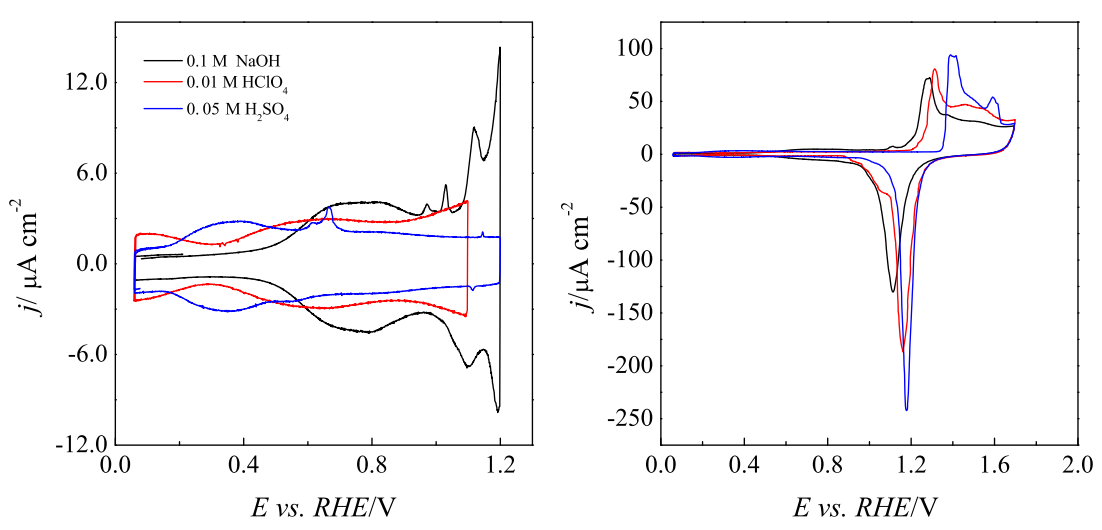

FIG. 1. Voltammetric profile of the single crystal Au bead electrode in different electrolytes. Scan rate: $0.05 \mathrm{~V} \mathrm{~s}^{-1}$. 
Voltammetric experiments were carried out using a waveform generator (EG\&EG PARC 175), a potentiostat (eDAQ EA161), and a digital recorder (eDAQ ED401).

\section{RESULTS AND DISCUSSION}

\section{A. Characterization of Pd-Au surfaces}

Figure 2 shows the electrochemical characterization of the different $\mathrm{Pd}$-Au surfaces prepared using the three methods described in Sec. II in $0.01 \mathrm{M} \mathrm{HClO}_{4}$. A window between 0.06 and $1.1 \mathrm{~V}$ is used so that the formation of Au surface oxides is avoided. For the $\mathrm{Au}$ (poly) electrode, the voltammogram shows the typical double layer obtained in this electrolyte. Upon the addition of $\mathrm{Pd}$, new features appear related to adsorption processes on the Pd layers. According to the characteristics of the voltammetric profile of Pd, described by Rand and Woods in the early 1970s, ${ }^{24}$ two main features are observed for a Pd electrode in acidic media: hydrogen adsorption/absorption processes at relatively high potentials, as compared to other metallic electrodes (up to $\sim 0.4 \mathrm{~V}$ ), and also Pd oxidationreduction processes at around $0.8 \mathrm{~V}$. For the Pd modified $\mathrm{Au}$ electrodes, these two processes can be distinguished. On one side, hydrogen adsorption can be observed at potentials below 0.4 V. However, due to the low amount of deposited Pd, the typical peaks due to hydrogen absorption do not appear. On the other hand, the oxidation/reduction processes of the adlayer are clearly visible at $\mathrm{E}>0.8 \mathrm{~V}$. It should be highlighted that the exact potential for these processes depends on the deposition method, indicating that they are affected by the Pd coverage and structure of the deposits.

Regarding the Pd coverage on each sample, in some cases, the peak related to the reduction of the Pd oxides has been used to estimate the coverage, assuming that in the reduction of a fully oxidized Pd monolayer, a charge of $424 \mu \mathrm{C} \mathrm{cm}^{-2}$ is exchanged. ${ }^{25,26}$ Additionally, the charge under the hydrogen adsorption region can also be employed to estimate the Pd surface area. However, the reference values have been obtained for massive Pd electrodes, and as aforementioned, both processes are affected by the underlying gold substrate and the structure of the deposit. Thus, a reliable estimation of the coverage cannot be made from these processes and only semi-quantitative

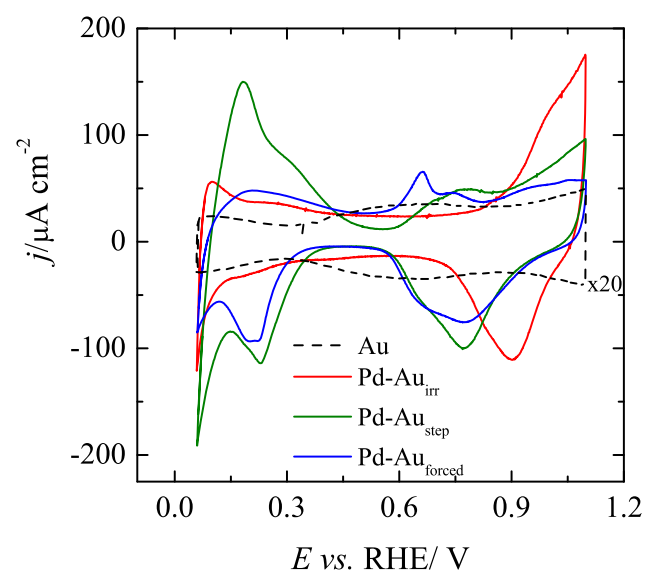

FIG. 2. Voltammetric profiles in $0.01 \mathrm{M} \mathrm{HClO}_{4}$ for Au and the different PdAu deposits prepared following the procedure described in Sec. II. Scan rate: $0.05 \mathrm{~V} \mathrm{~s}^{-1}$. considerations can be used. Hydrogen adsorption is, probably, the most reliable signal to estimate coverage values because in all cases appear in the same potential window. Using the charge for this process and $210 \mu \mathrm{C} \mathrm{cm}^{-2}$ as reference charge for an adsorbed hydrogen monolayer on $\mathrm{Pd}$, coverage values of $0.17,0.88$, and 0.37 for the $\mathrm{Pd}-\mathrm{Au}_{\mathrm{irr}}$, $\mathrm{Pd}-\mathrm{Au}_{\text {step }}$, and $\mathrm{Pd}-\mathrm{Au}_{\text {forced }}$, respectively, were obtained. From these values, it is clear that the Pd-Au $\mathrm{Air}_{\text {ir }}$ electrode is the surface with the lowest amount of $\mathrm{Pd}$, as demonstrated by the low charge of the hydrogen adsorption region and the more positive potentials required for the Pd oxide formation process. The higher potential for the Pd formation indicates that the interaction with the Au substrate (whose oxidation potential is higher than that of the Pd electrode) is larger, that is, Pd adatoms are mainly surrounded by Au atoms. Then, this low palladium coverage should correspond to the deposition of $\mathrm{Pd}$ in small islands along the Au substrate, mainly in the form of monolayers, in a similar configuration as that reported for $\mathrm{Ru}$ irreversible deposited on $\mathrm{Pt}(111)$ surfaces. ${ }^{27}$ When $\mathrm{Ru}$ is deposited using the same method, Ru complexes from the solution are initially adsorbed on the surface and are only reduced upon the immersion of the electrode in the electrochemical cell at the controlled potential. Thus, the coverage obtained is limited by the adsorption properties of the surface for the complexes, and in this case, the maximum Ru coverage obtained from the STM images is $\sim 20 \%$. This latter value is very similar to the one obtained here from the hydrogen adsorption charge for the $\mathrm{Pd}-\mathrm{Au}_{\text {irr }}$ electrode. Moreover, ruthenium adatoms are dispersed in small monoatomic islands homogeneously distributed over the surface. Owing to the voltammetric characteristics of the Pd deposits on the Au substrate, a similar structure can be inferred, and $\mathrm{Pd}-\mathrm{Au}_{\text {irr }}$ surfaces have the lowest amount of $\mathrm{Pd}$ on the gold substrate from the three samples, with small monoatomic Pd islands distributed over the $\mathrm{Au}$ surface.

The Pd- $\mathrm{Au}_{\text {step }}$ electrode is the richest in Pd of all the studied deposits, according to the estimated value and the definition of the Pd voltammetric characteristics. ${ }^{24}$ In spite of that, this electrode does not have the typical features of those found for a massive Pd electrode. This behavior suggests the formation of a Pd deposit which covers most of the gold surface with the probable formation of second and third layers of Pd in some places. ${ }^{20,28}$ Owing to the higher affinity of Pd for $\mathrm{Au}$, the expected growth mode is the Stranski-Krastanov mechanism. In a strict Stranski-Krastanov growth mode, the first layer is formed and completed prior to the formation of the second layer. From that, deposits in the third, fourth, and successive layers are formed well before the underlying layers are completed, giving rise to a rough surface for massive deposits. However, this ideal process in which the first layer is completed before the deposition in the second layer requires a precise control of the deposition conditions. In this case, Pd deposits should cover most of the surface, as the estimated coverage indicates, but the formation of the second and, probably, the third layer has already occurred. Despite the higher Pd coverage of this sample, the formation of bulk deposits is discarded because the electrochemical behavior is different from that measured for massive Pd electrodes, implying that they are clearly affected by the surface structure of the 
$\mathrm{Au}$ substrate. For hydrogen adsorption, this process appears at lower potentials (between 0.05 and $0.4 \mathrm{~V}$ ). Nevertheless, there is no presence of $\mathrm{H}_{\text {ads }}$ peaks observed in Pd electrodes. The absence of well-defined peaks can be attributed to the following: (i) hydrogen adsorption is hindered for Pd films on $\mathrm{Au} ;{ }^{19,29}$ (ii) the strong influence of the Au substrate (in such a way, the interactions and the deposition site of the Pd on the $\mathrm{Au}$ substrate depend on the atomic arrangement of the substrate) $;, 25,30,31$ or (iii) the different adsorption properties of the deposited Pd depending on its structure, which means that not all deposited $\mathrm{Pd}$ atoms are at the surface and thus available for the adsorption of hydrogen. ${ }^{25}$ Additionally, the oxide reduction peak appears at $0.77 \mathrm{~V}$, which coincides with the peak potential obtained by Pronkin and Wandlowski for $1 \mathrm{ML}$ of $\mathrm{Pd}$ on $\mathrm{Au}(111) .^{32}$

The forced deposition of $\mathrm{Pd}$ in $\mathrm{Au}$ by a reductive $\mathrm{H}_{2}$ atmosphere also provides to the electrodes the voltammetric characteristics of the palladium covered electrodes. ${ }^{24} \mathrm{Com}-$ paring with the deposits formed by Pd irreversible adsorption, hydrogen adsorption currents are higher, and the oxide region is displaced to negative potentials, indicating higher amounts of palladium on the substrate. In fact, this voltammetric profile resembles that obtained for the $\mathrm{Pd}-\mathrm{Au}_{\text {step }}$ surface, according to the hydrogen adsorption region and the onset potential for the oxide formation. The main difference between $\mathrm{Pd}-\mathrm{Au}_{\text {forced }}$ and $\mathrm{Pd}-\mathrm{Au}_{\text {step }}$ surfaces is the lower currents in the hydrogen adsorption region. Thus, it can be proposed that the surface structure is similar to that obtained for the $\mathrm{Pd}-\mathrm{Au}_{\text {step }}$ surface but with a lower fraction of the surface covered by $\mathrm{Pd}$, in accordance with the estimated coverage value calculated from the hydrogen adsorption charge. The difference from the previous deposition method is linked to the nature of the reduction process leading to the formation of the Pd layers. This deposition method uses hydrogen as a reductant, but with a controlled amount of $\mathrm{Pd}$, which is contained in the water droplet attached to the electrode when it is transferred to the vessel with the reductive hydrogen atmosphere. After some Pd is initially deposited on the Au surface, in a similar way as that obtained for the $\mathrm{Pd}-\mathrm{Au}_{\text {irr }}$, the high affinity of Pd for the adsorption of hydrogen with respect to Au should lead to a preferential reduction of the Pd complexes over the previously deposited Pd and not over the Au substrate. Thus, the deposition of the second layer of Pd starts well before the completion of the first layer and small Pd island will be formed with a multilayer structure. Then, the main difference between the $\mathrm{Pd}-\mathrm{Au}_{\text {forced }}$ and $\mathrm{Pd}-\mathrm{Au}_{\text {step }}$ is the amount of the $\mathrm{Au}$ surface covered by the $\mathrm{Pd}$ islands, but in both cases, Pd islands have a multilayer structure.

\section{B. Glycerol electrooxidation}

The electrocatalytic activity of Pd-Au electrodes towards glycerol electro-oxidation $\left(1 \times 10^{-4} \mathrm{M}-1 \times 10^{-1} \mathrm{M}\right)$ was evaluated in alkaline solution $(0.1 \mathrm{M} \mathrm{NaOH})$, as shown in Figs. 3-5. For comparison, the behavior of the pure gold electrode was added to the figures. In these figures, the first scan is shown, but no significant differences are observed upon cycling. As can be seen, the measured currents rise as the concentration increases, especially for the $\mathrm{Pd}-\mathrm{Au}_{\mathrm{irr}}$ electrode. Starting from the lower glycerol concentration, it is clear that adsorbed hydrogen for
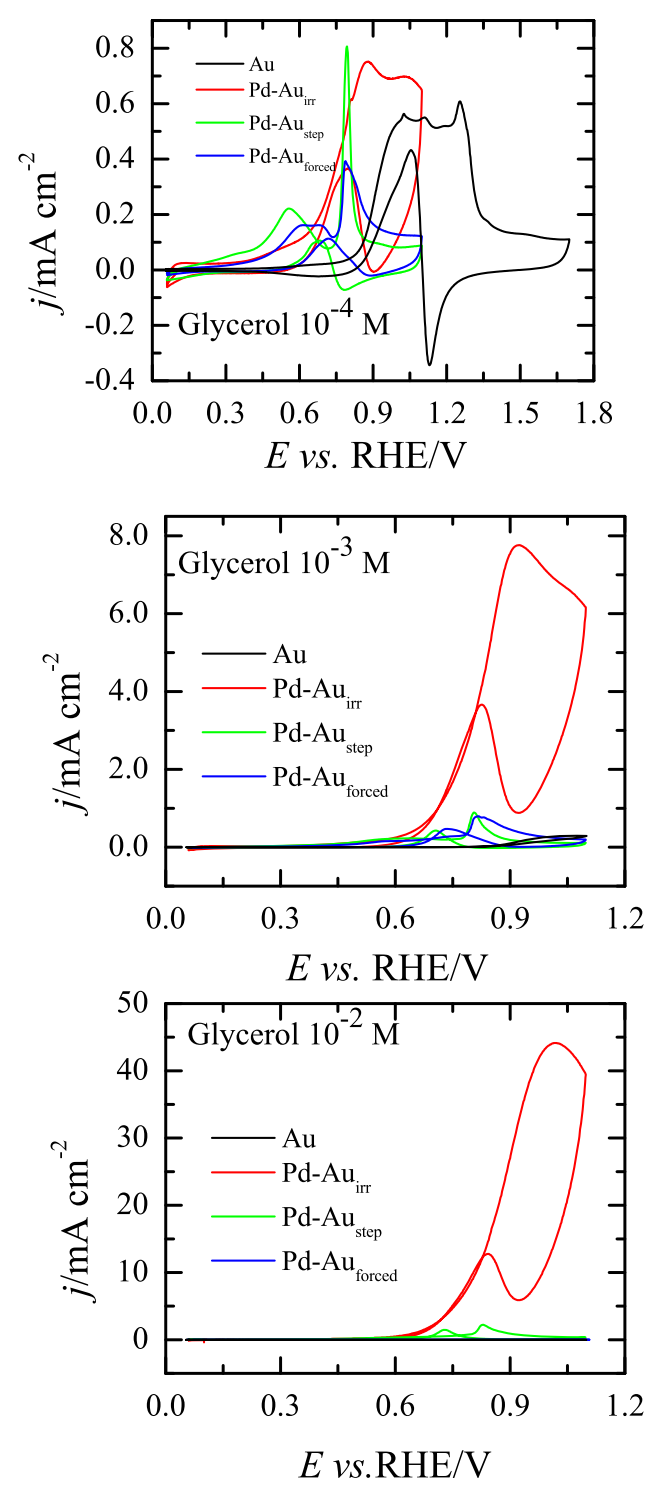

FIG. 3. Voltammetric profiles for glycerol oxidation in $0.1 \mathrm{M} \mathrm{NaOH}$ with different glycerol concentrations on the $\mathrm{Au}$ and $\mathrm{Pd}-\mathrm{Au}$ electrodes. Scan rate: $0.05 \mathrm{~V} \mathrm{~s}^{-1}$.

the $\mathrm{Pd}-\mathrm{Au}_{\text {step }}$ and $\mathrm{Pd}-\mathrm{Au}_{\text {forced }}$ electrodes has been inhibited because the hydrogen adsorption charge $0.4 \mathrm{~V}$ is significantly smaller than that recorded for the $\mathrm{Pd}-\mathrm{Au}_{\text {irr }}$ surface and that recorded in the absence of glycerol. This effect is also visible in Fig. 4, which shows an enlarged view to point out the onset potential for $1 \times 10^{-3} \mathrm{M}$ glycerol. The inhibition of hydrogen adsorption means that, for these deposits, some intermediate species are adsorbed on the surface at low potentials. The currents measured in $1 \times 10^{-4} \mathrm{M}$ are small, as expected, and a clear hysteresis is observed between the positive and negative scan directions.

For the $\mathrm{Pd}-\mathrm{Au}_{\mathrm{irr}}$ electrode, the onset potential for the oxidation is $\sim 0.6 \mathrm{~V}$, which is significantly lower than those obtained for the $\mathrm{Au}$ or Pd pure electrocatalysts. ${ }^{3-7,33}$ From this point, the current increases giving rise to a peak at $0.87 \mathrm{~V}$. Then, the current diminishes and, upon scan reversal, reaches a value close to zero around $0.9 \mathrm{~V}$, where the oxidation current raises again and a peak is observed at $0.81 \mathrm{~V}$. The presence of this hysteresis is related to the oxidation of the Pd layer. As 


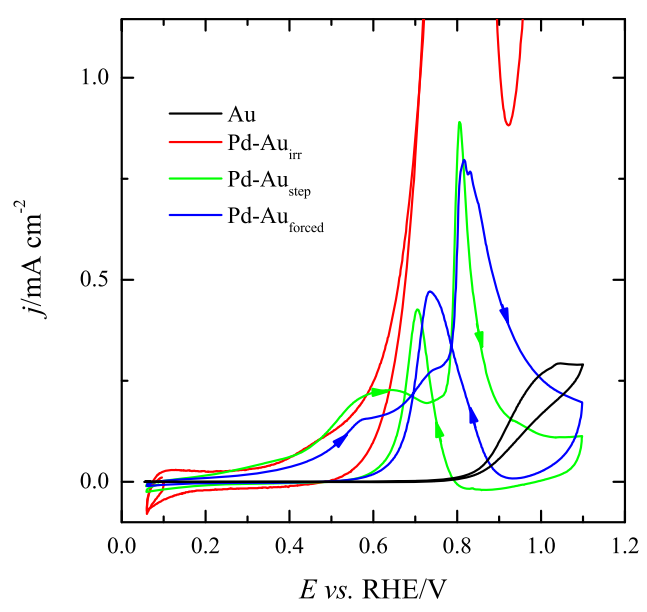

FIG. 4. Enlargement in the onset region of the voltammetric profiles for glycerol oxidation in $0.1 \mathrm{M} \mathrm{NaOH}+1 \mathrm{mM}$ glycerol on the $\mathrm{Au}$ and $\mathrm{Pd}-\mathrm{Au}$ electrodes. Scan rate: $0.05 \mathrm{~V} \mathrm{~s}^{-1}$.

shown in Fig. 2, the oxidation of Pd on this deposit starts at $0.9 \mathrm{~V}$, which is the point where the glycerol oxidation current reaches the maximum value. As the Pd surface oxide is being formed, the electrode deactivates, and the measured currents diminish. Then, in the negative scan direction, the reduction of the Pd surface oxides is completed at $0.8 \mathrm{~V}$, which is the potential where the currents in the negative scan direction attain, for this electrode, values comparable to those measured in the positive scan direction. From this point, the evolution of the current in the negative scan direction follows that measured in the positive scan direction.

For higher concentrations, the general behavior of the $\mathrm{Pd}-\mathrm{Au}_{\text {irr }}$ electrode is the same, but the currents increase significantly with the increase in concentration. For $1 \times 10^{-3} \mathrm{M}$ glycerol, peak currents are ten times higher than those measured for $1 \times 10^{-4} \mathrm{M}$ glycerol, which indicates that currents are linear with concentration. Moreover, the complete overlap between the positive and negative scan directions when the Pd adlayer is fully reduced shows that adsorbed species are not accumulated on the surface and all reaction products are diffusing to the bulk solution. For $1 \times 10^{-2}$ and $0.1 \mathrm{M}$ glycerol concentrations, the effect of the local $\mathrm{pH}$ change induced by

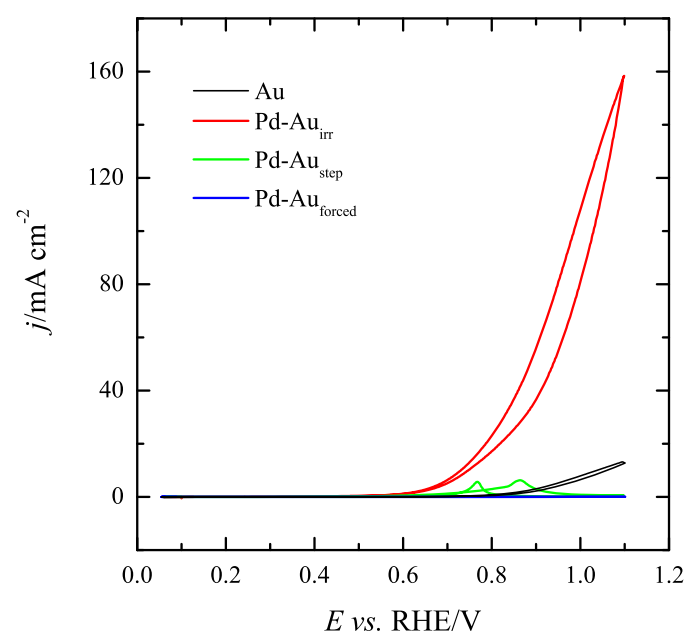

FIG. 5. Voltammetric profiles for glycerol oxidation in $0.1 \mathrm{M} \mathrm{NaOH}+0.1 \mathrm{M}$ glycerol on the Au and Pd-Au electrodes. Scan rate: $0.05 \mathrm{~V} \mathrm{~s}^{-1}$. the large currents and the concomitant $\mathrm{OH}^{-}$consumption/ $\mathrm{H}^{+}$ generation leads to a shift in the peak potentials to higher values, especially for the $1 \times 10^{-2} \mathrm{M}$ glycerol concentration.

The other two deposits, $\mathrm{Pd}-\mathrm{Au}_{\text {step }}$ and $\mathrm{Pd}-\mathrm{Au}_{\text {forced }}$, show a similar behavior and oxidation currents that are significantly smaller than those measured for the $\mathrm{Pd}-\mathrm{Au}_{\mathrm{irr}}$ electrode. Moreover, as the concentration increases, this difference in activity for these surfaces with the $\mathrm{Pd}-\mathrm{Au}_{\text {irr }}$ electrode becomes larger. It should be noted that the onset potential for the oxidation is similar to that measured for the $\mathrm{Pd}-\mathrm{Au}_{\text {irr }}$ surface, as can be clearly observed for $1 \times 10^{-4}$ and $1 \times 10^{-3} \mathrm{M}$ glycerol (Figs. 3 and 4). However, the voltammogram for the positive scan direction contains a broad wave around $0.6 \mathrm{~V}$ and a narrow peak at $\sim 0.8 \mathrm{~V}$. Both features are separated by a minimum in current at $\sim 0.7 \mathrm{~V}$. The peak potential at $0.8 \mathrm{~V}$ coincides with the onset of the oxide formation on the $\mathrm{Pd}$ layer, which again deactivates the surface. In the negative scan direction, the currents rise again when the Pd oxide layer is reduced, giving rise to a peak at $0.7 \mathrm{~V}$. The peak currents in the negative scan direction are higher than those measured in the positive scan direction for the same potential, indicating the presence of a poisoning species formed at low potentials in the positive scan direction. The formation of those species justifies the diminution in the current observed in the positive scan direction around $0.7 \mathrm{~V}$. As can be observed in Figs. 3 and 4 , the behavior of the $\mathrm{Pd}-\mathrm{Au}_{\text {step }}$ and $\mathrm{Pd}-\mathrm{Au}_{\text {forced }}$ electrodes is very similar. The major difference is that the currents for $\mathrm{Pd}-\mathrm{Au}_{\text {forced }}$ electrode are somehow smaller and the peaks are less defined. It should be noted that the voltammetric profiles reported here are comparable to those measured for Pd alloy nanoparticles. ${ }^{3}$

From the results presented here, it is clear that the electrochemical oxidation is significantly affected by the structure of the substrate. A recent study by Kong et al. ${ }^{34}$ points out the importance of synthesizing heterogeneous nanostructures for obtaining better electrocatalysts for reactions such as oxygen reduction or formic acid oxidation. For this reaction, the best results are obtained with the $\mathrm{Pd}-\mathrm{Au}_{\mathrm{irr}}$ electrode, in which small monoatomic Pd islands are distributed over the Au surface. For the other deposits in which the amount of free $\mathrm{Au}$ sites is significantly smaller and the islands have multiatomic high, currents are significantly lower. This fact points out that the key sites in the enhanced activity are ensembles of Pd-Au sites in the edges of the monoatomic Pd islands. Moreover, the oxidation of the Pd atoms leads to the deactivation of the site so that both $\mathrm{Au}$ and $\mathrm{Pd}$ are required for the oxidation of glycerol.

\section{Following the glycerol oxidation pathway reaction on $\mathrm{Au}$ and $\mathrm{Pd}-\mathrm{Au}$ surfaces}

The voltammetric results allow obtaining information about the reactivity of the Pd-Au deposits, but the final products of the reaction cannot be characterized. For a better understanding of the glycerol oxidation reaction and the intermediate and final products being formed during the electrochemical experiments, spectroscopic data are required. Figures 6 and 7 display the FTIR results for $1 \times 10^{-2} \mathrm{M}$ and $1 \times 10^{-1} \mathrm{M}$, respectively, providing information on the adsorbed species on the 

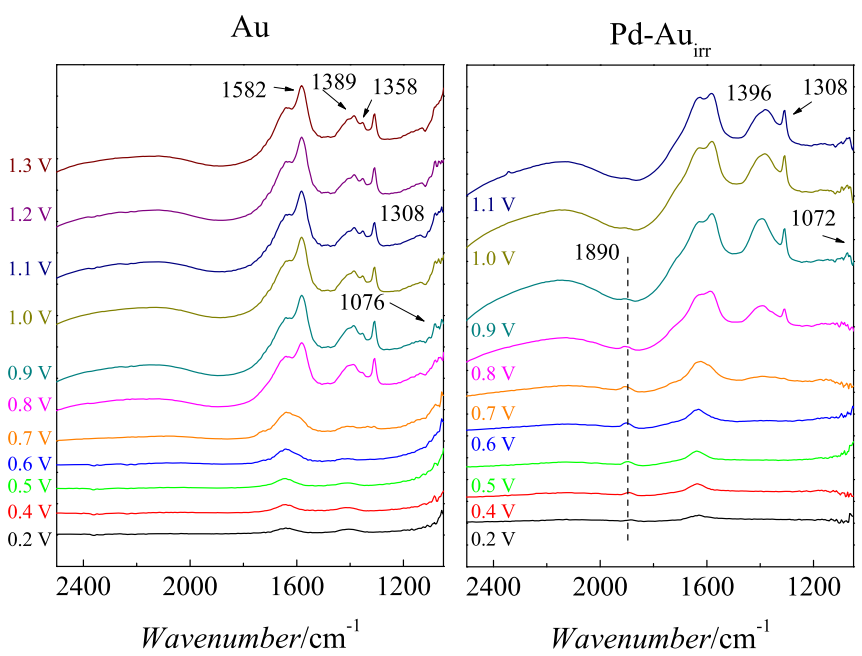

catalyst and the products formed during the glycerol electrooxidation. Spectra are presented for the bare gold, $\mathrm{Pd}-\mathrm{Au}_{\mathrm{irr}}$, and $\mathrm{Pd}-\mathrm{Au}_{\text {step }}$ electrodes. Due to the similar electrochemical behavior of the $\mathrm{Pd}-\mathrm{Au}_{\text {forced }}$ surface with that measured for the $\mathrm{Pd}-\mathrm{Au}_{\text {step }}$ electrode, experiments were not conducted for the Pd-Au $u_{\text {forced }}$ electrode. As can be seen, several bands are observed in the spectra acquired using the spectrum taken at $0.1 \mathrm{~V}$ as reference. Table I gives a list of the frequencies and adsorption modes involved in those bands.

The main goal in the glycerol electrooxidation is to achieve the complete oxidation to carbonate according to

$$
\begin{gathered}
\mathrm{CH}_{2} \mathrm{OH}-\mathrm{CHOH}-\mathrm{CH}_{2} \mathrm{OH}+20 \mathrm{OH}^{-} \\
\rightarrow 3 \mathrm{CO}_{3}^{2-}+14 \mathrm{H}_{2} \mathrm{O}+14 \mathrm{e}^{-} .
\end{gathered}
$$

However, the obtained FTIR spectra are complex and several bands related to the formation of products in an incomplete oxidation reaction are observed. These products include those in which the $\mathrm{C}-\mathrm{C}$ bond has not been broken such as glycerate, two-carbon products such as glycolate, or even one-carbon products such as formate. The main problem found during the interpretation of the results is the overlap of bands corresponding to these reaction products, mostly between 1300 and $1400 \mathrm{~cm}^{-1}$, which complicates the study. In this range of frequencies, vibration modes corresponding to formate,

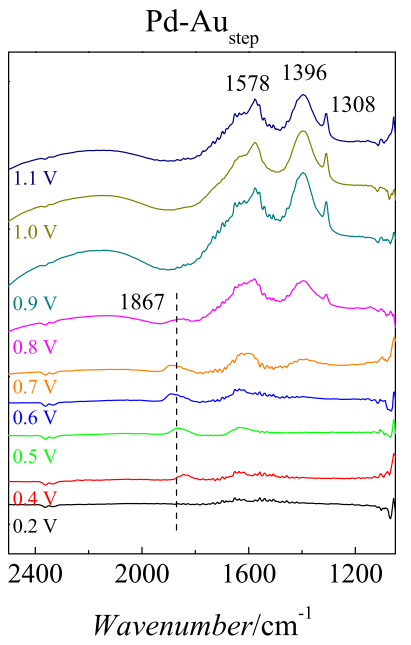

FIG. 6. FTIR spectra at different potentials for the $\mathrm{Au}, \mathrm{Pd}-\mathrm{Au}_{\mathrm{irr}}$, and $\mathrm{Pd}-\mathrm{Au}_{\text {step }}$ electrodes in $0.01 \mathrm{M}$ glycerol $+0.1 \mathrm{M}$ $\mathrm{NaOH}$. carboxylic acids, carbonate, and glycerate species are observed. For this reason, it is difficult to establish the exact and quantitative oxidation mechanism for glycerol. Instead, routes and partial oxidation products will be proposed from the observed spectral bands.

As shown in Table I, several bands related to the products of glycerol oxidation are found for both Figs. 6 and 7. For the Au electrode, bands at 1308 and $1389 \mathrm{~cm}^{-1}$ are assigned to the formation of glycerate in alkaline solutions $\mathrm{s}^{37,42}$ according to the reaction

$$
\begin{aligned}
& \mathrm{CH}_{2} \mathrm{OH}-\mathrm{CHOH}-\mathrm{CH}_{2} \mathrm{OH}+5 \mathrm{OH}^{-} \\
& \quad \rightarrow \mathrm{CH}_{2} \mathrm{OH}-\mathrm{CHOH}-\mathrm{COO}^{-}+4 \mathrm{H}_{2} \mathrm{O}+4 \mathrm{e}^{-} .
\end{aligned}
$$

Among all initial reaction routes, this is probably the most straightforward and facile. It should be noted that the oxidation of other alcohols in alkaline media, such as ethanol, give rises to the formation, almost exclusively, of the anion corresponding to the acid, ${ }^{43,44}$ constituting a typical route in the oxidation of alcohols which leads to the formation of the anions derived from the corresponding acid. Glycerate is also considered as the intermediate in the formation of hydroxipyruvate, according to the reaction

$$
\begin{aligned}
\mathrm{CH}_{2} \mathrm{OH}-\mathrm{CHOH}-\mathrm{COO}^{-}+2 \mathrm{OH}^{-} \rightarrow & \mathrm{CH}_{2} \mathrm{OH}-\mathrm{CO}-\mathrm{COO}^{-} \\
& +2 \mathrm{H}_{2} \mathrm{O}+2 \mathrm{e}^{-} .
\end{aligned}
$$
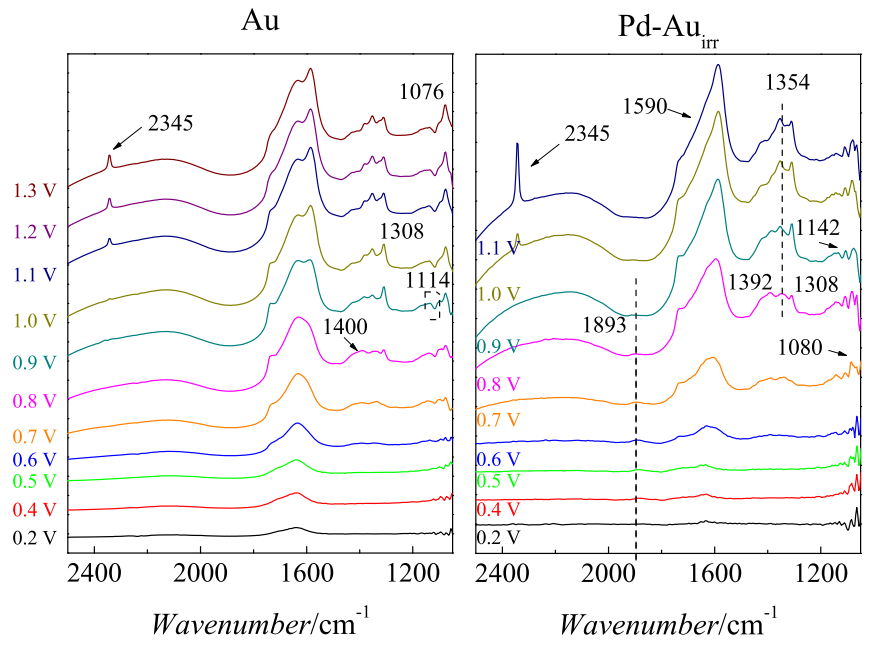

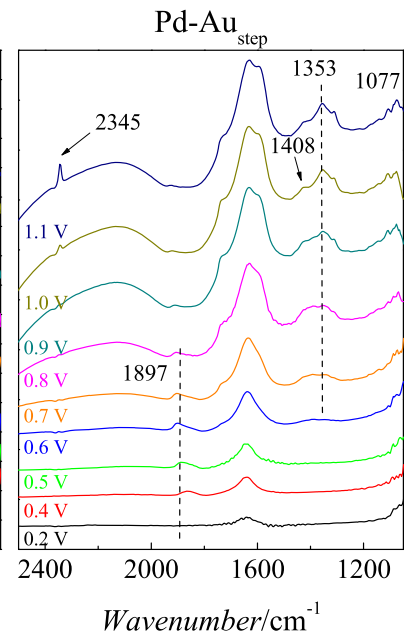

FIG. 7. FTIR spectra for the $\mathrm{Au}, \mathrm{Pd}-\mathrm{Au}$ irreversible adsorption, and Pd-Au step potential electrodes in $0.1 \mathrm{M}$ glycerol $+0.1 \mathrm{M} \mathrm{NaOH}$ at different potentials. 
TABLE I. Assignment of the IR bands observed in the spectra of Figs. 6 and 7 for glycerol electrooxidation.

\begin{tabular}{|c|c|c|c|}
\hline Wavenumber $\left(\mathrm{cm}^{-1}\right)$ & Vibration mode & Chemical species & References \\
\hline 2345 & $\mathrm{O}=\mathrm{C}=\mathrm{O}$ stretching & $\mathrm{CO}_{2}$ & 35 and 36 \\
\hline 1824-1902 & $\begin{array}{l}\text { Bridge-bonded } \mathrm{CO} \text { on } \\
\text { adsorbed } \mathrm{Pd} \text { atoms }\end{array}$ & $\mathrm{CO}_{\mathrm{B}}$ & 1 \\
\hline $1620-1700$ & $\mathrm{O}-\mathrm{H}$ bending band & $\mathrm{H}_{2} \mathrm{O}$ & 36 and 37 \\
\hline $1582-1585$ & $\begin{array}{l}\text { Asymmetric } \mathrm{O}-\mathrm{C}-\mathrm{O} \\
\text { stretching }\end{array}$ & Carboxylate ions & 1 and 38 \\
\hline $1392-1400$ & & $\begin{array}{l}\text { Carboxylic acid or } \\
\text { carbonate ions }\end{array}$ & $38-40$ \\
\hline $1384-1396$ & $\begin{array}{l}\text { Symmetric bending vibration } \\
\text { of glycerate adsorbed/ } \\
\text { symmetric } \mathrm{COO}^{-} \text {stretching }\end{array}$ & $\begin{array}{l}\text { Adsorbed carbonyl } \\
\text { species/glycerate }\end{array}$ & 1 and $40-42$ \\
\hline 1352 & Symmetric $\mathrm{C}-\mathrm{O}$ stretching & Formate & 38,40 , and 41 \\
\hline 1308 & $\mathrm{C}-\mathrm{O}$ stretching & Glycerate & 1,37 , and 40 \\
\hline $1070-1100$ & & Glycolate & 37 and 40 \\
\hline
\end{tabular}

An additional pathway observed for the gold electrode is the formation of glycolate. ${ }^{37,40,42}$ This species implies that the carbon chain has been broken into two fragments, one leading to the formation of glycolate, which gives rise to the band at $1076 \mathrm{~cm}^{-1}$, and $\cdot \mathrm{CH}_{2} \mathrm{OH}$ as the second fragment according to

$$
\begin{aligned}
& \mathrm{CH}_{2} \mathrm{OH}-\mathrm{CHOH}-\mathrm{CH}_{2} \mathrm{OH}+4 \mathrm{OH}^{-} \\
& \quad \rightarrow \mathrm{CH}_{2} \mathrm{OH}-\mathrm{COO}^{-}+\mathrm{CH}_{2} \mathrm{OH}_{\mathrm{ads}, \mathrm{Au}}+3 \mathrm{H}_{2} \mathrm{O}+3 \mathrm{e}^{-} .
\end{aligned}
$$

The $\mathrm{CH}_{2} \mathrm{OH}$ fragment is adsorbed on gold and can be further oxidized to yield formate or the desired final product, carbonate. It should be mentioned that the cleavage of the $\mathrm{C}-\mathrm{C}$ bond is normally a difficult step ${ }^{45}$ but this cleavage is activated by the presence of an alcohol group in each carbon. Thus, it has been found that this process is easier in ethylene glycol as compared to ethanol. ${ }^{46}$ According to Kong et al. ${ }^{34}$ Au sites are able to adsorb these fragments and produce formate and, later, carbonate anions promoted by adsorbed $\mathrm{OH}$ on gold, at potentials where formate is oxidized on gold in alkaline media, ${ }^{47}$

$$
\begin{aligned}
& \mathrm{CH}_{2} \mathrm{OH}_{\mathrm{ads}, \mathrm{Au}}+4 \mathrm{OH}^{-} \rightarrow \mathrm{COOH}_{\mathrm{ads}, \mathrm{Au}}+3 \mathrm{H}_{2} \mathrm{O}+4 \mathrm{e}^{-}, \\
& \mathrm{COOH}_{\mathrm{ads}, \mathrm{Au}}+\mathrm{OH}_{\mathrm{ads}, \mathrm{Au}}+2 \mathrm{OH}^{-} \rightarrow \mathrm{CO}_{3}^{2-}+2 \mathrm{H}_{2} \mathrm{O} .
\end{aligned}
$$

The appearance in the spectra of bands at 1358, 1385, and $1392 \mathrm{~cm}^{-1}$ coming from formate or carbonyl species agrees with reactions (5) and (6). ${ }^{36,41,48}$ Additionally, the band at $\sim 1400 \mathrm{~cm}^{-1}$ is originated by the carbonate production. ${ }^{42,43}$

The spectra obtained for the Pd deposits on Au have a qualitative band structure very similar to that measured on the pure Au electrode. However, some differences are observed. First, the presence of palladium adds a new route of oxidation, allowing the formation of adsorbed $\mathrm{CO}$ before carbonate production, as can be observed by the presence of the band at $\sim 1895 \mathrm{~cm}^{-1}$, associated with adsorbed $\mathrm{CO}$ on $\mathrm{Pd}$. Although $\mathrm{CO}$ can be adsorbed on gold electrodes when $\mathrm{CO}$ is present in solution and it promotes the oxidation of small molecules, ${ }^{49,50}$ its adsorption in the absence of solution $\mathrm{CO}$ is very weak, which allows to assign this band to $\mathrm{CO}$ adsorbed on Pd. Adsorbed $\mathrm{CO}$ comes from the oxidation of $\mathrm{CH}_{2} \mathrm{OH}$ fragments appearing after the cleavage of the molecule,

$$
\mathrm{CH}_{2} \mathrm{OH}_{\mathrm{ads}, \mathrm{Pd}}+3 \mathrm{OH}^{-} \rightarrow \mathrm{CO}_{\mathrm{ads}, \mathrm{Pd}}+3 \mathrm{H}_{2} \mathrm{O}+3 \mathrm{e}^{-} .
$$

Adsorbed CO blocks the surface, and it is only oxidized at potentials higher than $0.9 \mathrm{~V}$ on $\mathrm{Pd}$ according to

$$
\mathrm{CO}_{\mathrm{ads}, \mathrm{Pd}}+4 \mathrm{OH}^{-} \rightarrow \mathrm{CO}_{3}^{2-}+2 \mathrm{H}_{2} \mathrm{O}+2 \mathrm{e}^{-} .
$$

Comparing the spectra for both $\mathrm{Pd}-\mathrm{Au}$ samples, it can be observed that the band for $\mathrm{CO}_{\mathrm{ads}, \mathrm{Pd}}$ is more intense for the Pd$\mathrm{Au}_{\text {step }}$ electrode, regardless of the concentration. Moreover, it appears at $0.4 \mathrm{~V}$ and disappears at $0.9 \mathrm{~V}$. This behavior can be related to the differences in the positive and negative scan directions in the voltammogram observed for this electrode in Figs. 2 and 3. In the positive scan, the progressive adsorption of $\mathrm{CO}_{\mathrm{ads}}$,Pd leads to the diminution in between 0.6 and $0.7 \mathrm{~V}$ observed for the Pd-Au $\mathrm{Aurced}_{\text {for }}$ and $\mathrm{Pd}-\mathrm{Au}_{\text {step }}$ electrodes. The onset of the $\mathrm{CO}_{\text {ads,Pd }}$ oxidation leads to the increase in the currents, as additional sites are available for the oxidation of glycerol. In the negative scan direction, when the Pd oxides are reduced at $0.7 \mathrm{~V}$, the surface is free from $\mathrm{CO}_{\mathrm{ads}, \mathrm{Pd}}$ and, thus, currents are higher than that in the positive scan direction. In the Pd-Au $\mathrm{u}_{\text {irr }}$ electrode, the amount of $\mathrm{CO}_{\mathrm{ads}, \mathrm{Pd}}$ formed is always very small, and thus, no difference between both scans is observed.

The main quantitative difference between the spectra of Figs. 6 and 7 is the large $\mathrm{CO}_{2}$ band observed at the concentration of $0.1 \mathrm{M}$ for the $\mathrm{Pd}-\mathrm{Au}_{\text {irr }}$ electrode. The appearance of a $\mathrm{CO}_{2}$ band in alkaline solutions indicates significative $\mathrm{pH}$ change in the proximities of the working electrode due to the depletion of $\mathrm{OH}^{-}$anions as the oxidation reaction proceeds, as reported in Ref. 37 and 51. The large currents obtained for this electrode imply a huge $\mathrm{pH}$ diminution in the proximities of the thin layer region and the transformation of carbonate into $\mathrm{CO}_{2}$, as observed in Fig. 7. This $\mathrm{pH}$ change also has effects on the $\mathrm{O}-\mathrm{H}$ bending band of water, at around $1650 \mathrm{~cm}^{-1}$. However, this band overlaps with other bands related to the carboxylate and carboxylic acid, which precludes a detailed study during the glycerol oxidation reaction. 
The observance of a band for $\mathrm{CO}_{2}$ allows to perform a quantitative analysis of the spectra in Fig. 7. The formation of $\mathrm{CO}_{2}$ can be followed because its frequency appears in a separate region from the rest of the incomplete oxidation products, and thus it can be compared with the formation of all other possible intermediate products containing one, two, or three carbons. Absolute band intensities in the FTIR internal reflection mode depend strongly on the thin gap distance between the electrode and prism, and for this reason, they cannot be used for comparison between different experiments. However, ratios between band intensities are not affected by this and can be used to analyze the spectra. Thus, the ratio between the integrated bands for $\mathrm{CO}$ and $\mathrm{CO}_{2}$ at different potentials and that corresponding to the incomplete oxidation products (bands between 1300 and $1400 \mathrm{~cm}^{-1}$ ) measured at $1.1 \mathrm{~V}$ are displayed in Fig. 8.

Figure 8(a) shows that the onset potential for the $\mathrm{CO}_{2}$ /carbonate production is around $1 \mathrm{~V}$ for all the electrodes, irrespectively of the composition and activity. Before this potential value, no $\mathrm{CO}_{2}$ band is seen in the spectra of Fig. 6. Comparing the three electrodes, $\mathrm{Au}$ is the worst catalyst for $\mathrm{CO}_{2}$ formation, and the presence of $\mathrm{Pd}$ enhances the formation of $\mathrm{CO}_{2}$. In addition, the $\mathrm{Pd}-\mathrm{Au}_{\text {irr }}$ electrode shows the highest activity for this route in the three electrodes. It should be highlighted that, according to the electrochemical behavior shown in Fig. 3, this electrode has a large activity at potentials below $1 \mathrm{~V}$. Thus, the observation of $\mathrm{CO}_{2} /$ carbonate production only above $1 \mathrm{~V}$ implies that this reaction is only taking place under certain electrode potential conditions. Since the onset potential is the same for three studied electrodes, it can be said that the formation of $\mathrm{CO}_{2}$ /carbonate is linked to the activation of reactions (5) and (6) on the $\mathrm{Au}$ sites due to the adsorption of
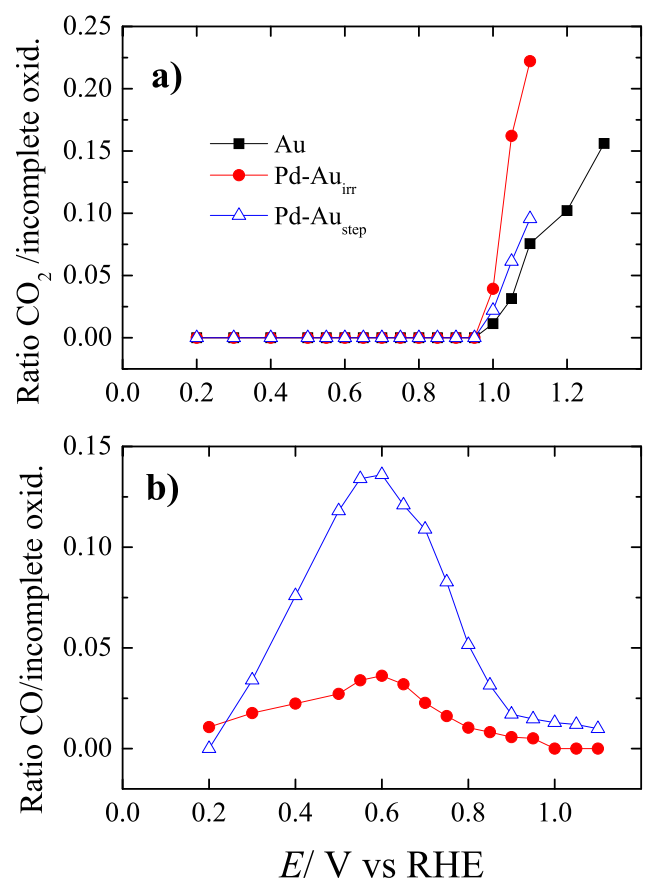

FIG. 8. Ratio between the integrated intensity of the bands for (a) $\mathrm{CO}_{2}$ at $2345 \mathrm{~cm}^{-1}$ and (b) $\mathrm{CO}$ band at $1860-1900 \mathrm{~cm}^{-1}$ at different potentials with respect to the integrated bands between 1230 and $1480 \mathrm{~cm}^{-1}$ at $1.1 \mathrm{~V}$, assigned to incomplete oxidation products such as glycerate, glycolate, or formate.
$\mathrm{OH}$ species. Thus, the higher activity of the $\mathrm{Pd}-\mathrm{Au}_{\mathrm{irr}}$ should then be related to a larger ability of this surface to break the $\mathrm{C}-\mathrm{C}$ bond in the glycerol molecule, linked to the presence of $\mathrm{Pd}$ and the activity of $\mathrm{Au}$ for the oxidation of one carbon fragments.

On the other hand, the amount of $\mathrm{CO}_{2} /$ carbonate formed in the reaction is not directly linked to the presence of adsorbed $\mathrm{CO}$, as Fig. 8(b) demonstrates. The amount of $\mathrm{CO}$ reaches a maximum at $0.6 \mathrm{~V}$, and from that potential, its oxidation proceeds until it is completely eliminated at $\sim 0.9 \mathrm{~V}$. Moreover, the amount of $\mathrm{CO}$ formed in the $\mathrm{Pd}-\mathrm{Au}_{\mathrm{irr}}$ is much smaller than that measured for the $\mathrm{Pd}-\mathrm{Au}_{\text {step }}$ electrode, implying that for this latter electrode, the formed $\mathrm{CO}_{2} /$ carbonate is not coming from $\mathrm{CO}$ but from the previously formed formate or adsorbed $\mathrm{CH}_{2} \mathrm{OH}$ species, highlighting the bifunctional role of the Pd-Au structure. The whole behavior observed here for the different $\mathrm{Pd}-\mathrm{Au}$ surfaces implies that $\mathrm{Pd}$ is more active for the cleavage of the $\mathrm{C}-\mathrm{C}$ bond, giving rise to the formation of one carbon fragments. These fragments evolve to yield adsorbed $\mathrm{CO}$, which deactivates the surfaces. However, in the monoatomic Pd islands, the transformation of the one carbon species into adsorbed $\mathrm{CO}$ does not take place, and these fragments are oxidized to carbonate/ $\mathrm{CO}_{2}$ by Au surface atoms.

\section{CONCLUSIONS}

Results provided here highlight the importance of the preparation method employed to obtain the palladium deposits on gold because of their different properties for electrocatalytic reactions such as glycerol oxidation. From all deposits tested, the $\mathrm{Pd}-\mathrm{Au}_{\mathrm{irr}}$ surface is considered as the one with more free gold sites, promoting a bifunctional mechanism for the glycerol oxidation, where carbonaceous fragments are adsorbed in Pd and later oxidized by the oxygenated species of gold. The substantial increase of the activity at the highest studied concentration confirms that those $\mathrm{Pd}-\mathrm{Au}$ ensemble sites are responsible for the catalysis. $\mathrm{Pd}-\mathrm{Au}_{\text {step }}$ is the surface with the highest amount of Pd on the surface, according to its voltammetric profile and favors the formation of $\mathrm{CO}$ adsorption on the catalyst before its oxidation to carbonate. FTIR results corroborate the activities observed for the voltammetric profiles, proving the formation of glycerate, glycolate, formate, and carbonate during the glycerol electrooxidation, and also confirm the results obtained in the voltammetric experiments. As a summary, $\mathrm{Pd}-\mathrm{Au}_{\text {irr }}$ surfaces show the best catalytic behavior for the complete oxidation route of glycerol oxidation due to the bifunctional role of the surface. Whereas Pd favors the cleavage of the $\mathrm{C}-\mathrm{C}$ bonds, Au favors the oxidation of one carbon fragments to carbonate/ $/ \mathrm{CO}_{2}$.

\section{ACKNOWLEDGMENTS}

This work has been financially supported by the Ministerio de Economía y Competitividad and Generalitat Valenciana by Project Nos. CTQ2016-76221-P and PROMETEOII/2014/013, respectively. G.A.B.M. also thanks her post-doctorate fellowship from $\mathrm{CNPq}$ (Grant No. PDE 233268/2014-6). 
${ }^{1}$ M. Simões, S. Baranton, and C. Coutanceau, ChemSusChem 5(11), 21062124 (2012).

${ }^{2}$ Z. Zhang, L. Xin, J. Qi, Z. Wang, and W. Li, Green Chem. 14(8), 2150-2152 (2012).

${ }^{3}$ B. T. X. Lam, M. Chiku, E. Higuchi, and H. Inoue, J. Power Sources 297, 149-157 (2015).

${ }^{4}$ A. N. Geraldes, D. F. da Silva, L. G. d. A. e Silva, E. V. Spinacé, A. O. Neto, and M. C. dos Santos, J. Power Sources 293, 823-830 (2015).

${ }^{5}$ A. N. Geraldes, D. F. Silva, J. C. M. Silva, R. F. B. Souza, E. V. Spinacé, A. O. Neto, M. Linardi, and M. C. Santos, J. Braz. Chem. Soc. 25, 831-840 (2014).

${ }^{6}$ A. N. Geraldes, D. F. da Silva, E. S. Pino, J. C. M. da Silva, R. F. B. de Souza, P. Hammer, E. V. Spinacé, A. O. Neto, M. Linardi, and M. C. dos Santos, Electrochim. Acta 111, 455-465 (2013).

${ }^{7}$ M. Mougenot, A. Caillard, M. Simoes, S. Baranton, C. Coutanceau, and P. Brault, Appl. Catal., B 107(3), 372-379 (2011).

${ }^{8}$ M. J. Llorca, J. M. Feliu, A. Aldaz, and J. Clavilier, J. Electroanal. Chem. 351(1), 299-319 (1993).

${ }^{9}$ E. Sibert, L. Wang, M. De Santis, and Y. Soldo-Olivier, Electrochim. Acta 135, 594-603 (2014).

${ }^{10}$ J. A. Rodriguez and D. W. Goodman, J. Phys. Chem. 95(11), 4196-4206 (1991).

${ }^{11}$ J. Rodriguez, R. A. Campbell, and D. W. Goodman, Surf. Sci. 307, 377-383 (1994).

${ }^{12}$ Y. Robach, M. Abel, and L. Porte, Surf. Sci. 526(3), 248-256 (2003).

${ }^{13}$ Y. Suo and I. M. Hsing, Electrochim. Acta 56(5), 2174-2183 (2011).

${ }^{14}$ Y.-H. Qin, Y. Li, R.-L. Lv, T.-L. Wang, W.-G. Wang, and C.-W. Wang, Electrochim. Acta 144, 50-55 (2014).

${ }^{15}$ L. Prati, A. Villa, F. Porta, D. Wang, and D. Su, Catal. Today 122(3), 386-390 (2007).

${ }^{16}$ M. Simões, S. Baranton, and C. Coutanceau, Appl. Catal., B 93(3), 354-362 (2010).

${ }^{17}$ P. Quaino, E. Santos, H. Wolfschmidt, M. A. Montero, and U. Stimming, Catal. Today 177(1), 55-63 (2011).

${ }^{18}$ M. Baldauf and D. M. Kolb, J. Phys. Chem. 100(27), 11375-11381 (1996).

${ }^{19}$ L. A. Kibler, M. Kleinert, R. Randler, and D. M. Kolb, Surf. Sci. 443(1), 19-30 (1999).

${ }^{20}$ L. A. Kibler, M. Kleinert, and D. M. Kolb, Surf. Sci. 461(1), 155-167 (2000).

${ }^{21}$ L. A. Kibler, M. Kleinert, V. Lazarescu, and D. M. Kolb, Surf. Sci. 498(1), 175-185 (2002).

${ }^{22}$ B. Álvarez, V. Climent, J. M. Feliu, and A. Aldaz, Electrochem. Commun. 2(6), 427-430 (2000).

${ }^{23}$ T. Iwasita and F. C. Nart, Prog. Surf. Sci. 55(4), 271-340 (1997).

${ }^{24}$ D. A. J. Rand and R. Woods, J. Electroanal. Chem. Interfacial Electrochem. 36(1), 57-69 (1972).

${ }^{25}$ I. Srejić, M. Smiljanić, B. Grgur, Z. Rakočević, and S. Štrbac, Electrochim. Acta 64, 140-146 (2012).

${ }^{26}$ X. Wang, B. Tang, X. Huang, Y. Ma, and Z. Zhang, J. Alloys Compd. 565, $120-126$ (2013).
${ }^{27}$ E. Herrero, J. M. Feliu, and A. Wieckowski, Langmuir 15(15), 4944-4948 (1999).

${ }^{28}$ M. Takahasi, K. Tamura, J. Mizuki, T. Kondo, and K. Uosaki, J. Phys.: Condens. Matter 22(47), 474002 (2010).

${ }^{29}$ M. Baldauf and D. M. Kolb, Electrochim. Acta 38(15), 2145-2153 (1993).

${ }^{30}$ M. Smiljanić, I. Srejić, B. Grgur, Z. Rakočević, and S. Štrbac, Electrochim. Acta 88, 589-596 (2013).

${ }^{31} \mathrm{~T}$. Kondo, T. Masuda, and K. Uosaki, in X-Ray and Neutron Techniques for Nanomaterials Characterization, edited by C. S. S. R. Kumar (SpringerVerlag Berlin Heidelberg, 2016), pp. 367-449.

${ }^{32}$ S. Pronkin and T. Wandlowski, Surf. Sci. 573(1), 109-127 (2004).

${ }^{33}$ J.-h. Zhang, Y.-j. Liang, N. Li, Z.-y. Li, C.-w. Xu, and S. P. Jiang, Electrochim. Acta 59, 156-159 (2012).

${ }^{34}$ F. Kong, C. Du, J. Ye, G. Chen, L. Du, and G. Yin, ACS Catal. 7(11), 7923-7929 (2017).

${ }^{35}$ A. Zalineeva, A. Serov, M. Padilla, U. Martinez, K. Artyushkova, S. Baranton, C. Coutanceau, and P. B. Atanassov, J. Am. Chem. Soc. 136(10), 3937-3945 (2014).

${ }^{36}$ A. C. Garcia, Y. Y. Birdja, G. Tremiliosi-Filho, and M. T. M. Koper, J. Catal. 346(Suppl. C), 117-124 (2017).

${ }^{37}$ D. Z. Jeffery and G. A. Camara, Electrochem. Commun. 12(8), 1129-1132 (2010).

${ }^{38}$ A. C. Garcia, C. Morais, T. W. Napporn, K. B. Kokoh, and G. TremiliosiFilho, ChemElectroChem 4(6), 1314-1319 (2017).

${ }^{39}$ J. González-Cobos, S. Baranton, and C. Coutanceau, J. Phys. Chem. C 120(13), 7155-7164 (2016).

${ }^{40}$ V. L. Oliveira, C. Morais, K. Servat, T. W. Napporn, G. Tremiliosi-Filho, and K. B. Kokoh, J. Electroanal. Chem. 703(Suppl. C), 56-62 (2013).

${ }^{41}$ P. S. Fernández, M. E. Martins, and G. A. Camara, Electrochim. Acta 66(Suppl. C), 180-187 (2012).

${ }^{42}$ N. E. de Souza, J. F. Gomes, and G. Tremiliosi-Filho, J. Electroanal. Chem. 800(Suppl. C), 106-113 (2017).

${ }^{43}$ C. Busó-Rogero, E. Herrero, and J. M. Feliu, ChemPhysChem 15(10), 20192028 (2014).

${ }^{44}$ C. Busó-Rogero, J. Solla-Gullón, F. Vidal-Iglesias, E. Herrero, and J. Feliu, J. Solid State Electrochem. 20(4), 1095-1106 (2016).

${ }^{45}$ J. Souza-Garcia, E. Herrero, and J. M. Feliu, ChemPhysChem 11(7), 13911394 (2010).

${ }^{46}$ R. M. Arán-Ais, E. Herrero, and J. M. Feliu, Electrochem. Commun. 45, 40-43 (2014).

${ }^{47}$ G. L. Beltramo, T. Shubina, and M. Koper, "Oxidation of formic acid and carbon monoxide on gold electrodes studied by surface-enhanced Raman spectroscopy and DFT," ChemPhysChem 6(12), 2597 (2005).

${ }^{48}$ J. Schnaidt, M. Heinen, D. Denot, Z. Jusys, and R. Jürgen Behm, J. Electroanal. Chem. 661(1), 250-264 (2011).

${ }^{49}$ P. Rodriguez, A. A. Koverga, and M. T. M. Koper, Angew. Chem. Int. Ed. 49(7), 1241-1243 (2010).

${ }^{50}$ P. Rodriguez, Y. Kwon, and M. T. M. Koper, Nat. Chem. 4(3), 177-182 (2012).

${ }^{51}$ R. M. L. M. Sandrini, J. R. Sempionatto, E. Herrero, J. M. Feliu, J. SouzaGarcia, and C. A. Angelucci, Electrochem. Commun. 86, 149-152 (2018). 